\section{Hanyang Medical Revilews}

Hanyang Med Rev 2014;34:91-95

http://dx.doi.org/10.7599/hmr.2014.34.2.91

pISSN 1738-429X eISSN 2234-4446

\section{스트레스와 정신건강 평가를 위한 설문 도구}

황인환 · 오동훈

한양대학교 의과대학 정신건강의학교실 및 한양대학교 정신건강연구소

\title{
Questionnaires for Assessing Stress and Mental Health
}

\author{
In Hwan Hwang, Dong Hoon Oh
}

Department of Psychiatry, College of Medicine and Institute of Mental Health, Hanyang University, Seoul, Korea

Psychological factors can influence physical health. The relationship between psychological stress and physical disease is evident in everyday clinical practice and therefore, assessing stress and mental health has been an important issue in clinical practice and research. This review discusses the assessment of stress and mental health by examining the psychometric parameters and other qualities of some of the best-known instruments used to assess stress and mental health. At present, the questionnaire method is the most popular for measuring stress and mental health status. There are many different kinds of questionnaires for assessing mental stress; each questionnaire has its own advantages and disadvantages. The authors' intend to evaluate and summarize useful questionnaires for assessing stress and mental health in order to aid in choosing the appropriate questionnaire according to the clinical purpose of the examination.

Key Words: Stress, Psychological; Mental Health; Psychometrics; Questionnaire

\author{
Correspondence to: Dong Hoon Oh \\ 우 133-791, 서울시 성동구 왕십리로 222, \\ 한양대학교 의과대학 정신건강의학교실 \\ Department of Psychiatry, Hanyang \\ University College of Medicine, \\ 222 Wangsimni-ro, Sundong-gu, \\ Seoul 133-791, Korea \\ Tel: +82-2-2290-8423 \\ Fax: +82-2-2298-2055 \\ E-mail: odh@hanyang.ac.kr \\ Received 4 March 2014 \\ Revised 18 April 2014 \\ Accepted 23 April 2014 \\ This is an Open Access article distributed under
the terms of the Creative Commons Attribution
Non-Commercial License (http://creativecom-
mons.org/licenses/by-nc/3.0) which permits un-
restricted non-commercial use, distribution, and
reproduction in any medium, provided the origi-
nal work is properly cited.
}

\section{서 론}

정신과 신체의 관계는 질병을 주술적 의식으로 치료하려고 하였 던 원시, 고대시대부터 통합적으로 보는 시각이 있었다. 이후 그리 스 문화에서도 히포크라테스의 4 체액설 등이 주목받으며 신체와 정신 또는 영혼을 모두 치료해야 한다고 생각하였고, 이러한 통합 적인 접근방식은 현대의 방식과 비슷하다. 르네상스 시기를 거치며 데카르트의 정신-신체 이원론이 널리 인정되었다. 또한, 과학의 발 달로 인해 신체 질환에서의 정신작용에 대한 중요성은 상대적으로 줄어들며, 인간 전체보다는 질병 자체만을 치료하려는 분위기가 우 세해 왔다.

그러던 중 1818년, Johann Christian Heinroth가 불면증의 원인 에 대해 설명하며 처음으로 psychosomatic 정신신체라는 용어를
사용하였고, 1895 년 프로이트는 히스테리경련 등 신체화 과정을 설 명하며 감정과 무의식과 같은 정신활동이 신체 증상으로 표현된 것 으로 보았다. 1922년 즈음하여 내과의사였던 Felix Deutsch가 정신 신체의학이라는 용어를 소개한 것으로 알려져 있으며, 심리적 효 과에 의한 질병의 증상 완화에 대해 집중하였다[1]. 이러한 정신과 신체의 연관성에 대한 관심이 증가하며 현대의 정신신체의학이 발 전하였고, 더불어 정신건강영역에서의 자문조정의학의 중요성이 인정되었다. 또한, 질병의 예후와 치료에 있어서 정신건강의학적 상 태의 평가가 중요하게 생각되며, 정확한 평가를 위한 다양한 설문 도구들이 개발되어 왔다. 국내에서도 국내의 실정을 반영하여 번역 과 보완이 이루어졌고, 이에 대한 타당도 연구도 활발히 이루어지 고 있다.

본 연구에서는 정신건강을 평가하기 위해 스트레스, 인지, 정서, 
사회적 관계 등 여러 영역에서 널리 사용되고 있는 평가도구들을 소개하고자 한다. 특히 그 중에서 한국어로 번역이 되었고, 이에 대 한 국내에서의 타당도 연구가 이루어졌으며, 진료현장에서 쉽게 사 용할 수 있는 자가보고형식의 평가도구를 다루도록 하겠다.

\section{본 론}

\section{1. 스트레스영역}

1) 생활 사건 스트레스 평가

외국에서 Holmes와 Rahe가 일상생활에서 겪을 수 있는 스트레 스를 평가하기 위해 개발한 Social Readjustment of Rating Scale (SRRS)[2]과 같은 종류의 설문으로 1984년 Lee에 의해 우리나라 실 정에 맞게 고안된 설문이다. 이미 30 년이 지난 평가도구로 현재 국 내 실정에 맞추어 보완, 개발해야 할 필요성이 있다[3].

\section{2) Brief encounter psychosocial instrument (BEPSI, BEPSI-K)}

1988년 Frank 등에 의해 개발된 스트레스 평가 척도이며[4], 1996 년에 Yim 등에 의해 한국어판 BEPSI (BEPSI-K)이 개발되었다[5]. 총 다섯 가지 문항으로 이루어져 있으며, 지난 한 달간의 스트레스 에 대해 평가할 수 있도록 만들어졌다. 각 문항은 0-4점으로 평가하 고 합하여 평균을 구한 값이 2.4점 이상인 경우에 스트레스가 있는 것으로 볼 수 있다[5]. 문항이 적고, 간단하기 때문에 일차진료 상황 에서 편리하게 사용할 수 있는 장점이 있다.

\section{3) 인지적 스트레스 반응 척도(cognitive stress response scale, CSRS)}

2004년 고경봉 등이 개발한 스트레스를 받은 후 일어나는 인지 적 반응에 관한 문항을 통해 스트레스 반응 중 인지적 측면을 측정 하는 도구이다. 총 21 개의 문항을 통해 3 가지 측면, 극단-부정적 사 고, 공격-적대적 사고, 자기비하적 사고를 평가하며, 문항이 간단하 여 일차진료 현장에서 쉽게 사용할 수 있다[6].

\section{2. 인지영역}

1) 간이정신상태검사(mini mental status examination, MMSE)

Folstein 등이 1975년에 인지기능의 평가를 위해 개발한 도구로 짧은 시간 동안의 간단한 검사를 통해 지남력, 기억, 집중력 등의 인 지기능을 쉽게 평가할 수 있으며, 질병의 진행과정 동안 반복 측정 함으로써 상태의 변화 및 경과를 볼 수 있다는 장점이 있다[7]. 이는 인지기능의 장애를 보이는 환자들을 일차적으로 평가하는 데 있어 서 임상에서 많이 사용되고 있으며, 간단하고 신뢰도와 타당도가 잘 검증된 인지기능 평가도구이다[7]. 그러나 피검자의 연령, 교육 수준, 언어, 문화 등이 평가결과에 영향을 미친다는 것이 알려져 있 으며[8], 이러한 문제점이 고려되어 국내 실정에 적합한 개정판들이
개발되어 1989년에는 Kwon과 Park이 표준화한 MMSE-K [9], 1997 년에는 Kang 등이 표준화한 K-MMSE [10], 2002년에는 Lee 등이 표준화한 MMSE-KC [11]가 소개되었다. MMSE-K의 경우 25점 이 상을 확정적 정상, 21-24점을 인지기능 장애 의심, 20 점 이하를 확 정적 인지기능 장애로 구분하였으나[12], 각 검사마다 절단점의 차 이를 보이고 있었다. 이러한 이유로 2010년에는 Kim 등이 치매 선 별의 신뢰도와 정확도를 높이고, 단일화된 치매 평가도구를 개발 하기 위해 mini mental status examination for dementia screening (MMSE-DS)와 그 단축형인 SMMSE-DS를 개발하였으며, SMMSEDS의 경우 K-MMSE, MMSE-KC, MMSE-DS보다 통계적으로 유 의한 수준으로 높은 치매 진단 정확도를 보이고 있었고, 절단점은 14/15점으로 할 때 우수한 민감도, 특이도를 나타내었다[13]. 일차 진료 현장뿐만 아니라 치매 조기검진 사업 등 다양한 분야에서 적 합한 선별도구로서 활용하기 위하여 꾸준한 연구가 필요할 것으로 보인다.

\section{3. 정서영역}

1) 우울

(1) Beck depression inventory

Beck 등이 1961년에 개발한 자가보고형의 우울증상의 정도를 측정하는 도구로서 일반인뿐만 아니라, 임상집단에서도 유효성이 입증되어 전 세계적으로 널리 사용되고 있다[14]. 지난 1주일간의 기분을 확인할 수 있는 21 문항으로 구성되어 있으며, 이미 기술되 어 있는 4 개의 진술 중 자신에게 가장 적절하다고 생각되는 하나를 선택하여(0-4점), 우울증의 인지적, 정서적, 동기적, 신체적 증상 영 역을 평가하고 있다[15]. 1986년 Hahn 등에 의해 한국판 Beck 우울 척도(beck depression inventory - Korean version)가 처음 소개되 었으며[16], 우울증의 심각도 평가를 위해 Lee 등은 남자의 경우 16-19점, 여자의 경우 17-20점이 우울경향이 있는 사람, 남자의 경 우 20-23, 여자의 경우 21-24점이 우울증, 남자의 경우 24점 이상, 여 자의 경우 25 점 이상을 심한 우울증으로 분류하였다[17]. 그러나 자 가보고형 평가는 우울증상에 대한 주관적인 느낌에 의존하기 때 문에 나이, 성별, 학력, 성격 등과 같은 피검자의 특성에 따라 점수 가 달라질 수 있는 한계가 있기 때문에 점수에만 의존하여 진단하 는 것은 주의해야 한다[18].

\section{(2) Center for epidemiologic studies depression scale (CES-D)}

1971년에 Roth와 Locke에 의해 미국 정신보건연구원(NIMH)에 서 일반 인구 집단을 대상으로 우울 증후군의 역학적 연구를 하기 위해 개발되었으며, 1977년에 Radloff가 우울증상의 유무와 심한 정도를 측정하는 비진단적 검사로 개발하여, 선별도구로서 비교적 편하게 사용되고 있다. 자가보고형 척도에 간결한 문항이 장점이며, 역학연구에 많이 쓰이고 있다[19]. 지난 1주일 동안의 우울한 증상 
을 20개의 문항을 통해 평가하며, 각 문항당 0-3점으로 총점은 60 점이다. 임상적으로 의미가 있다고 생각되는 절단점은 미국과 일본 은 16점으로 받아들여지고 있다[20,21]. 1993년 Cho 등은 한국어 판에 대한 국내의 진단적 타당성 연구를 통해 국내 실정에 맞는 절 단점을 제시하였고, 임상환자군 대상으로 정신과 의사가 DSM 기 준의 주요 우울증을 진단하기 위해서는 25점을, CES-D의 본래 목 적인 지역사회 역학연구의 일차 선별 목적에서는 21 점을 절단점으 로 설정하는 것이 높은 예민도와 낮은 가음성률을 보인다고 제시 하였다[22].

\section{(3) Patient health questionnaire-9 (PHQ-9)}

Patient health questionnaire는 1999년에 Spitzer가 일차진료기 관에서 쉽게 볼 수 있는 정신질환의 진단을 위해 자가보고형식으 로 개발한 도구이며, PHQ-9은 이 중 우울증을 평가하는 도구이다 [23]. 총 9문항으로 구성되어 있으며, DSM-IV의 우울삽화의 진단기 준에 맞추어 고안되었다. 각 문항은 0-3점으로 계산하여 총 27점이 며, 0-4점은 우울증이 아님, 5-9점은 가벼운 우울증, 10-19점은 중 간 정도 우울증, 20-27점은 심한 우울증으로 평가한다. 다른 우울 증 선별검사들에 비해 짧고, 민감도와 특이도가 높아 일차진료 환 경에서 쉽게 사용할 수 있는 장점이 있다. 한글로 번역된 PHQ-9는 몇 종류가 있으며, Choi 등[24], Park 등[25], An 등[26]이 표준화 연 구 및 타당도 연구를 통해 한글 번역본의 국내에서의 유용성을 입 증하였다.

(4) Geriatric depression scale (GDS, GDS-15)

Geriatric depression scale (GDS)는 1983년 Yesavage가 고령인구 대상으로 우울증을 평가하기 위해 만든 자가보고형 척도이다[27]. 총 30 문항으로 이루어졌으며, 피검자는 예/아니요로 응답하는 형 식이다. 이후 15 문항으로 단축된 GDS-15가 개발되었으며, 여러 연 구들에서 노인 우울증을 평가하는 데 신뢰도와 타당도를 보였다 [28]. 국내에서는 한국 노인들의 정서에 맞고, 이해하기 쉬운 표현으 로 수차례 수정, 보완하며 번역이 이루어졌고, 높은 민감도, 특이도 를 보였으며, 절단점은 18점으로 보았다[29]. 쉬운 문항과 예/아니요 의 간단한 응답으로 이루어진 자가보고형태이나 노인의 경우 주의 력, 이해력 등의 인지기능의 감소와 시력저하 등의 문제로 검사자 를 통한 문답형식의 검사가 제안된다.

\section{2) 불안}

(1) Beck anxiety inventory (BAI)

불안과 우울을 구분하고, 진단하는 것은 중요하면서도 과거부터 많은 어려움이 있어왔다. 이 둘을 구분할 수 있는 검사도구의 필요 성에 기초하여 1988년 Beck 등이 많은 표본수를 대상으로 불안장 애에서 나타나는 불안을 측정하기 위하여 beck anxiety inventory
(BAI)를 개발하였으며, 우울로부터 불안을 구별해내기 위한 자가 보고형식의 도구로 만들어져 불안 정도를 측정하는 데 사용되고 있다[30]. 총 21문항이며 각 문항당 0-3점으로 평가되며, 0-9점을 정 상수준, 10-18점은 경한 수준의 불안, 19-30점을 심한 수준의 불안, 31-63점을 매우 심한 수준의 불안으로 구분하고 있다. 한글 번역된 한국어판 BAI가 국내에서도 사용되고 있으며, 이를 사용하여 불 안을 평가할 수 있고, 우울과 구분해 낼 수 있다는 국내 연구가 이 루어져 있다[31].

(2) 병원 불안-우울 척도(hospital anxiety and depression scale, HADS) 1983년 Zigmond 등이 일반병원을 방문한 환자들이 진료를 받 기 위해 기다리는 시간 동안 병원에서 나타나는 불안-우울 정도를 측정하기 위해 개발한 14 문항으로 구성된 척도이다[32]. 7개의 홀 수 문항은 불안을 7 개의 짝수 문항은 우울을 측정할 수 있도록 구 성되어 있으며, 각 문항은 0-3점으로 총점은 불안, 우울 각각 21점 으로 계산된다. 1999년에는 Oh 등이 이를 한글화 번역하여 국내에 서의 표준화 연구를 시행하였으며, 불안, 우울 항목 모두 절단점을 8점으로 하였을 때 높은 민감도와 특이도를 보였다. 일차진료 및 정 신과 외의 진료과에서 쉽고, 짧은 시간 내에 검사하여 불안과 우울 장애 환자들을 선별할 수 있는 척도로 사용되고 있다[33].

\section{(3) Mini international neuropsychiatric interview (MINI)}

1988년에 미국의 Sheehan과 프랑스의 Lecruiber가 주축이 되어 DSM-IV와 ICD-10을 기반으로 만든 구조화된 정신과적 면담 도 구이다[34]. 신뢰도, 타당도가 높으면서도, 검사시간은 20-30분 정 도로 짧은 장점을 갖고 있다. 검사방법도 쉬워서 면담자는 MINI에 제시된 문항을 그대로 환자에게 읽어서 질문하고, 환자의 예/아니 요 대답에 따라 화살표를 따라가다 보면 진단에 도달하게 되어 있 다. 국내에서는 2006년 Yoo 등이 번역하여 한국어판 MINI (K$\mathrm{MINI}$ 가 사용되고 있으며[35], 진단적 일치도가 양호하며, 특히 불 안장애에서 높은 진단적 일치도를 보이고 있었다. 그러나 면담자가 필요하다는 단점으로 인하여, 진단적 일치도가 높은 불안장애 중 3 가지(공황장애, 범불안장애, 사회불안장애)와 주요 우울장애를 포 함하여 4 개 질환에 대해 평가할 수 있는 단축된 자가보고형태의 MINI가 개발되어 사용되고 있다[36]. 39문항으로 이루어져 검사 소요시간이 짧아, 일차진료현장 및 정신과 외래 대기시간에 사용 할 수 있는 유용성을 보인다.

\section{4. 사회적 관계}

1) Lubben social network scale (LSNS)

1988년에 Lubben이 노인의 사회적 관계망을 측정하기 위해 사회 적 지지와 사회적 고립도를 평가하는 10 문항으로 이루어진 lubben social network scale (LSNS)를 개발하였고[37], 이후 가족, 이웃, 친 
구의 사회 관계망이 보완되어 18 문항으로 이루어진 확장판(LSNS18)[38], 12문항으로 이루어진 개정판(LSNS-R), 6 문항으로 이루어 진 축소판(LSNS-6)이 개발되었다. 기존의 10 문항으로 이루어진 LSNS의 확장판(K-LSNS-18)은 한글화 작업이 되어 국내에서 신뢰 도, 타당도 연구가 진행되어 유용성이 입증되었다[39].

각 문항당 0-5점으로 측정되며, 총점이 높을수록 사회적 관계망 이 높은 것으로 볼 수 있다. 10 문항으로 이루어진 원저에는 총점 50 점에서 20 점 이하의 경우에 사회적 고립의 위험이 크다고 판단하였 으나[37], 아직 국내 기준이 마련되지는 않아 향후 지속적인 연구가 필요할 것으로 보인다.

\section{2) Medical outcomes study-social support survey (MOS-SSS)}

1991년에 the read and medical outcomes study (MOS) team이 사회적 기능과 사회적 지지 정도를 통해 사회적 건강을 판단하기 위해 만든 척도이며[40], 국내에서는 2003년에 Lim 등이 번역하여 사용되고 있다[41]. 물질적 지지, 애정적 지지, 긍정적 사회 상호작 용, 정서적/정보적 지지의 19 문항으로 이루어져 있으며 각 문항은 0-4점이며, 총점은 100 점으로 환산하여 계산하고, 점수가 높을수 록 사회적 지지가 좋다는 것을 뜻한다.

\section{5. 그 외}

1) 간이정신진단검사(symptom checklist-90-revision,

\section{SCL-90-R)}

1970 년대에 Derogatis 등은 정신건강을 진단하기 위하여 90 개의 문항으로 이루어진 symptom checklist-90 (SCL-90)를 개발하였고 [42], 1983년에는 현재 사용하고 있는 개정판(symptom checklist90-revision, SCL-90-R)을 발표하였다[43]. 90개의 문항은 신체화, 강박증, 대인예민성, 우울, 불안, 적대감, 공포불안, 편집증, 정신증의 9가지 증상 영역을 포함하며 전반적인 정신건강을 평가할 수 있도 록 만들어졌고, 국내에서는 1984년에 Kim과 Kim이 번역하고 표준 화하여 사용되고 있다[44]. 현실 검증력의 저하가 있는 정신병 환자 들의 자가보고 형태의 검사를 그대로 신뢰하기 어려운 등 검사결과 를 그대로 진단에 사용하는 데에는 아직 무리가 있다는 의견이 많 지만, 90 문항의 자가보고형태라는 비교적 간단한 검사를 통해 다양 한 영역에서 정신건강을 평가할 수 있다는 데 의의가 있어 보인다.

\section{결 론}

정신건강의학과 진료 영역뿐만 아니라 다양한 진료영역에서 스 트레스와 정신건강의 정확한 평가는 중요하다. 이는 정신건강의학 적 상태가 신체 질환에 영향을 줄 수 있고, 반대로 신체질환으로 입 원한 환자가 다양한 심리적 반응을 보이는 것과 같이 신체질환 또 한 정신건강에 영향을 줄 수 있기 때문이다. 따라서 신체질환으로
진료를 보는 경우에도, 정신건강의학적 접근이 더해진다면, 환자가 받는 진료의 만족도를 높일 수 있을 것이다. 이러한 필요성에 의해 쉽고, 간단하며, 진단적 정확성이 높은 정신건강 평가도구들이 끊 임없이 개발되고, 보완되고 있다.

한 설문 도구가 모든 정신건강 영역을 포함하여 평가하기 어렵기 때문에, 각 설문이 어떤 증상 평가에 유용한지에 대한 정확한 지식 을 갖고 있어, 목적에 부합하는 적절한 설문도구 채택이 중요하다. 또한 각 도구들의 유의한 절단점을 알고 있어 환자가 개입이 필요한 수준의 결과를 보고한다면 정신과 진료 및 자문 등의 도움을 제공 하는 등 진료 현장에서 활용할 수 있을 것이다.

본 원고에서는 스트레스와 인지, 정서, 사회적 관계망을 포함하 여 정신건강을 평가할 수 있는 다양한 검사도구들 중 국내에서 사 용 가능한 자가보고형식의 평가도구에 대해 살펴보았다. 물론 이 외에도 많은 검사기간이 소요되고, 숙련된 검사자가 필요한 더 정 교한 검사들이 있지만, 정신과가 아닌 진료상황에서도 쉽게 사용 할 수 있는 짧은 문항의 자가보고형식의 평가도구로 범위를 제한하 여 소개하였다. 본 원고는 임상가들이 다양한 진료 영역에서 정신 건강 평가에 대해 더욱 관심을 갖고, 평가도구를 활용할 수 있도록 하는 데에 의의가 있다. 나아가 한국인의 정신역동과 한국의 사회, 문화 등의 실정을 더욱 잘 반영할 수 있도록 기존의 평가도구들을 보완하고, 개발하려는 노력이 필요하겠다.

\section{REFERENCES}

1. Lipsitt DR. Consultation-liaison psychiatry and psychosomatic medicine: the company they keep. Psychosom Med 2001;63:896-909.

2. Holmes TH, Rahe RH. The social readjustment rating scale. J Psychosom Res 1967;11:213-8.

3. Lee PS. A methodological research on the measurement of stress. Unpublished PhD thesis. Seoul: the graduate school of Nursing Science, Yonsei University; 1984:138.

4. Frank SH, Zyzanski SJ. Stress in the clinical setting: the brief encounter psychosocial instrument. J Fam Pract 1988;26:533-9.

5. Yim JH, Bae JM, Choi SS, Kim SW, Hwang HS, Huh BY. The validity of modified Korean-translated BEPSI (Brief Encounter Psychosocial Instrument) as instrument of stress measurement in outpatient clinic. J Korean Acad Fam Med 1996;17:42-53.

6. Koh KB, Park JK. Development of the cognitive stress response scale. J Korean Neuropsychiatry Assoc 2004;43:320-8.

7. Folstein MF, Folstein SE, McHugh PR. "Mini-mental state". A practical method for grading the cognitive state of patients for the clinician. J Psychiatry Res 1975;12:189-98.

8. Escobar JI, Burnam A, Karno M, Forsythe A, Landsverk J, Golding JM. Use of the Mini-Mental State Examination (MMSE) in a community population of mixed ethnicity. Cultural and linguistic artifacts. J Nerv Ment Dis 1986;174:607-14.

9. Kwon YC, Park JH. Korean version of Mini-Mental State Examination (MMSE-K): Part I. Development of the test for the elderly. J Korean Neuropsychiatry Assoc 1989;28:125-35.

10. Kang YW, Na DL, Han SH. A vailidity study on the Korean Mini-Mental 
State Examination (K-MMSE) in dementia patients. J Korean Neurol Assoc 1997; 15:300-8.

11. Lee JH, Lee KU, Lee DY, Kim KW, Jhoo JH, Kim JH, et al. Development of the Korean version of the Consortium to Establish a Registry for Alzheimer's Disease Assessment Packet (CERAD-K): clinical and neuropsychological assessment batteries. J Gerontol B Psychol Sci Soc Sci 2002; 57:P47-53.

12. Park JH, Park YN, Ko HJ. Modification of the mini-mental state examination for use with the elderly in a non-western society. Part II: Cutoff points and their diagnostic validities. Int J Geriatr Psychiatry 1991;6:875-82.

13. Kim TH, Jhoo JH, Park JH, Kim JL, Ryu SH, Moon SW, et al. Korean version of mini mental status examination for dementia screening and its' short form. Psychiatry Investig 2010;7:102-8.

14. Beck AT, Steer RA, Garbin MG. Psychometric properties of the beck depression inventory-25 years of evaluation. Clin Psychol Rev 1988;8:77100.

15. Beck AT, Ward CH, Mendelson M, Mock J, Erbaugh J. An inventory for measuring depression. Arch Gen Psychiatry 1961;4:561-71.

16. Hahn HM, Yum TH, Shin YW, Kim KH, Yoon DJ, Chung KJ. A standardization study of beck depression inventory in Korea. J Korean Neuropsychiatry Assoc 1986;25:487-500.

17. Lee MK, Lee YH, Park SH, Son CH, Jung YJ, Hong SG, et al. A Standardization Study of Beck Depression Inventory 1-Korean Version (K-BDI). Korean J Psychopathol 1995;4:77-95.

18. Domken M, Scott J, Kelly P. What factors predict discrepancies between self and observer ratings of depression? J Affect Disord 1994;31:253-9.

19. Radloff LS. The CES-D Scale: a self-report depression scale for research in the general population. Appl Psychol Meas 1977;1:385-401.

20. Roberts RE, Rhoades HM, Vernon SW. Using the CES-D scale to screen for depression and anxiety: effects of language and ethnic status. Psychiatry Res 1990;31:69-83.

21. Shima S, Shirano T, Kitamura T. New rating scale for depression. Clin Psychiatry 1985;42:865-78.

22. Cho MJ, Kim KH. Diagnostic validity of the CES-D (Korean version) in the Assessment of DSM-III-R major depression. J Korean Neuropsychiatry Assoc 1993;32:381-99.

23. Kroenke K, Spitzer RL, Williams JB. The PHQ-9: validity of a brief depression severity measure. J Gen Intern Med 2001;16:606-13.

24. Choi HS, Choi JH, Park KH, Joo KJ, Ga H, Ko HJ, et al. Standardization of the Korean version of patient health questionnaire- 9 as a screening instrument for major depressive disorder. J Korean Acad Fam Med 2007; 28:114-9.

25. Park SJ, Choi HR, Choi JH, Kim KW, Hong JP. Reliability and validity of the Korean version of the patient health questionnaire-9 (PHQ-9). Anxiety Mood 2010;6:119-22.

26. An JY, Seo ER, Lim KH, Shin JH, Kim JB. Standardization of the Korean version of screening tool for depression (Patient Health Questionnaire-9, PHQ-9). J Korean Soc Biol Ther Psychiatry 2013;19:47-56.

27. Yesavage JA. Geriatric depression scale. Psychopharmacol Bull 1988;24: 709-11.
28. Mitchell AJ, Bird V, Rizzo M, Meader N. Diagnostic validity and added value of the geriatric depression scale for depression in primary care: a meta-analysis of GDS30 and GDS15. J Affect Disord 2010;125:10-7.

29. Jung IK, Kwak DI, Shin DK, Lee MS, Lee HS, Kim JY. A reliability and validity study of geriatric depression scale. J Korean Neuropsychiatry Assoc 1997;36:103-22.

30. Beck AT, Epstein N, Brown G, Steer RA. An inventory for measuring clinical anxiety: psychometric properties. J Consult Clin Psychol 1988; 56:893-7.

31. Yook SP, Kim JS. A clinical study on the Korean version of beck anxiety inventory: comparative study of patient and non-patient. Korean J Clin Psychol 1997;16:185-97.

32. Zigmond AS, Snaith RP. The hospital anxiety and depression scale. Acta Psychiatry Scand 1983;67:361-70.

33. Oh SM, Min KJ, Park DB. A study on the standardization of the hospital anxiety and depression scale for Koreans: a comparison of normal, depressed and anxious groups. J Korean Neuropsychiatry Assoc 1999;38:289-96.

34. Sheehan DV, Lecrubier Y, Sheehan KH, Amorim P, Janavs J, Weiller E, et al. The Mini-International Neuropsychiatric Interview (M.I.N.I.): the development and validation of a structured diagnostic psychiatric interview for DSM-IV and ICD-10. J Clin Psychiatry 1998;59 Suppl 20:22-33;quiz 4-57.

35. Yoo SW, Kim YS, Noh JS, Oh KS, Kim CH, Namkoong K, et al. Validity of Korean version of mini international neuropsychiatric interview. Anxiety Mood 2006;2:50-5.

36. Lim SW, Song HS, Oh YH, Shin HC, Cho KH, Chung SK. A validation study of the abbreviated self-rated Korean version of MINI (MINI Patient Health Survey). Anxiety Mood 2007;3:32-40.

37. Lubben JE. Assessing social networks among elderly populations. Health Promot Maint 1988;11:42-52.

38. Lubben JE, Gironda M. Centrality of social ties to the health and well-being of older adults. In Berkman B, Harootyan L, Eds. Social work and health care in an aging society. New York: Springer Publishing; 2003:31950 .

39. Lee KW, Kim SY, Chung W, Hwang GS, Hwang YW, Hwang IH. The validity and reliability of Korean version of lubben social network scale. Korean J Fam Med 2009;30:352-8.

40. Sherbourne D, Stewart AL. The MOS social support survey. Soc Sci Med 1991;32:750-14.

41. Lim MK, Kim MH, Shin YJ, Yoo WS, Yang BM. Social support and selfrated health status in a low income neighborhood of Seoul, Korea. Korean J Prev Med 2003;36:54-62.

42. Derogatis LR, Lipman RS, Covi L. SCL-90: an outpatient psychiatric rating scale--preliminary report. Psychopharmacol Bull 1973;9:13-28.

43. Derogatis LR. SCL-90-R: administration, scoring, and procedures manual II. Baltimore: Johns Hopkins University School of Medicine, Clinical Psychometric Research; 1983.

44. Kim JH, Kim GI. The standardization study of symptom checklist-90-revision in Korea III. Ment Health Res 1984;2:278-311. 